\title{
Parágrafos sobre a poesia moçambicana contemporânea - sonho e violência, viagem e loucura, confissão e memória
}

\author{
Ana Mafalda Leite \\ Universidade de Lisboa
}

RESUMO: O ARTIGO CARACTERIZA ALGUMAS DAS TENDÊNCIAS DA POESIA MOÇAMBICANA PUBLICADA NO SÉCULO XXI, E OS TÓPICOS DESENVOLVIDOS PELOS POETAS.

ABSTRACT: THIS ESSAY AIMS TO DISCUSS SOME OF THE TOPICS OF THE MOZAMBICAN POETRY PUBLISHED ON THE TWENTIETH ONE CENTURY.

PALAVRAS-CHAVE: EROTISMO, SONHO, VIOLÊNCIA, VIAGEM, LOUCURA, CONFISSÃO, MEMÓRIA.

KEYWORDS: EROTICISM, DREAM, VIOLENCE, TRAVEL, MADNESS, CONFESSION AND MEMORY. 
os últimos dez anos surgiram vários livros de poemas de autores moçambicanos, que têm em comum uma aproximada data de nascimento: a década de setenta. Podemos designá-los como pertencentes a uma Geração, que começa a publicar em revistas e jornais na década de noventa, mas cuja publicação em livro praticamente se inicia no século XXI, sendo que alguns deles não chegaram ainda a fazê-lo, porque as condições editoriais mudaram com a privatização do mercado do livro.

Neste mesmo período, a prática de recitais e de declamação de poemas reuniu e continua a reunir muitos jovens, que amam e escrevem poesia, mostrando o interesse por esta arte, performatizada e dramatizada ao vivo. Assim, a poesia continua muito viva em Moçambique, e alguns nomes se destacam, já com publicação em livro ou em vias de tal acontecer. Animadores culturais, debatendo o estado da literatura do país, movimentando-se entre o desejo do "novo" e a leitura da herança literária dos poetas das gerações anteriores, são seduzidos pela poesia do mundo, deslocando-se para outros lugares experimentais, como a música e as artes plásticas. A prática experimental é híbrida, expressando-se por vários tipos de dicção como, por exemplo, o exercício da poesia, da prosa poética, de uma escrita tipo diário, ou de contos e novelas, parecendo ser uma tônica na escrita dos jovens autores. A qualidade dos textos de Ruy Ligeiro, Domi Chirongo, Dinis Muhai, Jorge Matine, Sangare Okapi e Tânia Tomé, entre vários outros, mostra como o panorama poético do país está em processo de renovação e de mutação.

Há no enquadramento histórico da nação vários acontecimentos que transformam as escolhas temáticas e a enunciação dos autores do século XXI. Entre estas novas vozes e o percurso iniciado em Charrua (que os dois poetas agora "mais velhos", Eduardo White e Armando Artur, despoletaram), continuado pelos poetas da geração de noventa de Xiphefo (como o caso de Guita Júnior e de Mohamed Kadir) e intermediado pela singular qualidade de escrita de um poeta como Nelson Saúte ou ainda pela publicação diversificada de Rogério Manjate e de Adelino Timóteo - verificamos nestas novas vozes surgidas uma postura de sujeitos em desajustamento entre a sua realidade, e a realidade exterior, como que à margem da sociedade, ou em processo de deslocamento.

São poetas que se enunciam socialmente "desenquadrados", "ex-cêntricos", espectadores críticos dos poderes, da corrupção, das desigualdades sociais, do uso indevido das armas, das misérias e fragilidades do quotidiano. 
O posicionamento deste novo sujeito poético, comum à maioria das vozes, é de distanciamento e de perplexidade perante a sua sociedade atual. O descentramento do sujeito poético toca o campo psicológico e o sentimental, e a desadequação é também ideológica, cultural e geográfica. Esse deslocamento é também de género, como no caso das novas dicções femininas, em que se revelam, de forma não convencional, a emoção e o desejo de uma mulher sujeito, enquanto diferença e conquista de um lugar individual-social.

A estrutura por vezes dramática de algumas das obras mostra um distanciamento crítico entre o sujeito enunciador, a incompatibilização entre o mundo e o poeta, que se desdobra em actor e espectador do dramático Theatrum mundi que o circunda, exercitando a poesia como uma forma temporal, que ganha estatuto de memória-consciência. Assim, a poesia é uma forma-abrigo, criada para compensar a desfasagem entre o eu e o mundo; a brecha criada entre ser e estar, entre o sujeito e a realidade social, permite ao poeta, homo faber, usar a palavra para criar um mundo alternativo, fazer-se matéria e cosmos verbal.

A desarticulação das utopias retoma em voz off um livro inaugural nesta perspectiva, As Falas do Escorpião de Eduardo White, e envereda por uma escrita organizada numa espécie de exterioridade observadora, narrativo-confessional, às vezes orquestrada pelos sons do "rap" e da poesia musical, em que a denúncia da violência, do mal-estar, é exemplar e fragmentariamente apresentada.

Estes modos enunciativos prendem-se, entre muitos outros factores, após o fim da guerra civil, com o desenvolvimento veloz que a sociedade moçambicana tomou, no advento de uma sociedade capitalizada, pelo desenvolvimento desigual, pela prevalência do surgimento de uma sociedade tecnológica voraz, pelo desenvolvimento de um mercado da cultura, com forte impacto também no campo editorial.

Escolho neste artigo os livros de três autores, apenas como uma forma de iniciar uma reflexão (que irá alongar-se em outro momento) contemplando poetas que perfazem um núcleo irradiador de procedimentos retóricos diversos e de novas propostas temático-formais. 


\section{A enunciação do sujeito feminino: escrita do sonho e do corpo na poesia de Sónia Sultuane}

Tem a poesia esse dom de fingir todas as verdades, todas as emoções, de se querer do sonho a presença, a totalidade e perfeição. No primeiro livro de poemas de Sónia Sultuane, Sonhos, a poeta percorre o espaço que vai de si própria para uma outra em que se procura e desafia, "como queria ser a outra dos meus sonhos" (S, p.47), feminino sujeito que se quer intenso e pleno no seu sensitivo imaginário, por entre as pausas de um cadenciado ritmo de escrita.

"Menina ainda tornei-me mulher/enfrentei o mundo, e a mim mesma" (S, p.15): um percurso que reflecte os sentimentos e sensualmente os convoca em todas as suas contradições. Desejo, ausência, saudade, ilusão, sonho, distância, alegria, dor. Imaginando através das palavras, as formas que têm os sentimentos, de tanto os sentir. Imaginando o amor, vivendo-o nessas imagens que ele encontra nos muitos espelhos da alma: "Amar-te é algo sem dimensão ou justificação/ é viver sempre na imaginação/ .../estar sempre a sonhar” (S, p.28).

No mundo amoroso imaginado pela escrita, a poeta tenta regressar à envolvência da infância e à candura excessiva de ser, "deixem-me no meu mundo doce e infantil, mas meu”( $\mathrm{S}, \mathrm{p} .13)$, experimentando-se ludicamente, ao brincar com o seu pensamento da emoção, refazendo-o pela distância, inventando-o, sem mágoa, com a alquimia já criativa da palavra: "vou brincando com o meu pensamento,/tentando encontrar-me distante,/ mas presente,/ no que és presente, quando és ausente" (S, p.38).

Torna-se o amador na coisa amada à custa de tanto imaginar, e a beleza procurada está em si, nessa invenção sensorial, que se filtra e ilumina entre ser e escrever, revelando-se devagar. Procura dos versos que levam Sónia a querer achar em si outras imagens de ser, em que o desejo se imagina e fulgura, fonte misteriosa que desprende a emoção. Nesse "sonho desperto" (S, p.38) a vontade de volver a uma imagem múltipla, em que narcisicamente se reinventa, enquanto personagem, tal como ao amor e seus imaginados sentidos, se descobre a poeta em palavra, a desejar ser totalidade, plenitude, sonho desperto em poema: "como queria ser a outra dos meus sonhos, alegre, misteriosamente bela/ e que não vagueia lentamente e triste,/ mas que vive,/ a beleza que arde tão dentro, como queria ser a outra, a dos meus sonhos mais viva ternamente" (S, p.47). 
Não é fácil escrever poemas sobre o amor quando esse mesmo tema percorre séculos de escrita na literatura. No entanto, encontramos nestes fragmentos confessionais/poemas, a singularidade narcísica da constituição do corpo, enquanto emoção, sua exposição e questionamento.

$\mathrm{Na}$ sua segunda coleetânea de poemas, Imaginar o Poetizado, a autora assume quase uma reivindicação da forma de sentir e do ser amoroso, tornando a sua reflexão mais sensorial e menos reflexiva, ao escrever sobre o prazer, a força erótica e a assumpção de um erotismo social, secularmente negado à mulher. Nessa perspectiva, os poemas de Sónia Sultuane, além de muito femininos, são também insinuantemente inconformistas pela temática sensorial e seu desnudamento emocional. Como fragmentos confessionais amorosos, estes textos suspendem-se na intemporalidade - o amor está em todos os tempos e vive sempre no presente - em que a recordação é sempre um aeto de presentificação dos sentidos, e a ausência dela, morte e deformação: "quando recorde só os teus olhos, não o teu olhar,/ a tua sombra, não o teu corpo,/ os teus beijos, não o teu gosto,/ os teus ecos, não as tuas palavras, quando todos os sentidos estiverem mortos" (IP, p. 31).

Obsessivamente, como que saboreando pedaços de "nogat": "deixavasme trincar o teu doce,/ e a cada mordidela,/sentia os teus lábios de mansinho,/ como podia esquecer-me desse sabor/ a torrado, de cor de canela,/ cor desses teus lábios adocicados,/ onde hoje trinco e mordo,/ à procura desse néctar,/com o mesmo gosto a "Nogat"(IP, p.13) - a poeta tenta descrever o sabor - sentir, feito corpo, na travessia entre o conhecido e o desconhecido, entre desejo, força, arrebatamento, e o medo, que se torna similarmente crescente, como a invasão de uma sombra, que a leva aos patamares da cegueira, zona de provável escuridão: "olho-me, sinto-me profundamente/ vontade, desejo,/ toco-me, entrego-me a mim.../entrego-me a esta escuridão/ mete medo...neste medo" (IP, p.59).

O corpo está cravado em cada um dos poemas, e de cada um deles se evola ou solta um aroma, uma forma de taeto, de paladar, de som, de concretas imagens. Os cinco sentidos são insuficientes para a captação integral do sentir amoroso, corporiamente inebriado. Feminina por excelência, esta forma de implicação da escrita, como corpo, erotiza a letra/som, que se inscreve entre pele e pena, e entre voz e verbo; há um arrebatamento e uma fisicidade da palavra que a torna concreta, sensível. 
Palavra poética nascida dos sentidos, que renasce em amorosa vulnerabilidade, exibindo um corpo, que fala, diz, contradiz, vibra, linguagens não codificadas, na sua surpresa de acontecimento, de dádiva e de entrega. O amor que nos poemas de Sónia Sultuane se faz revelação não é apenas um amor da alma, mas do corpo, um verbo feito carne, encarnação. A alma que o sopra é apenas o início do rastilho que acende a explosão de todos os físicos sentidos: "A tua alma, a alma das almas,/ já a viste? Já com ela falaste? Já a sentiste?/ deixa-me-rir"(IP, p.41).

O poema "Africana" amplifica o tema da identidade, uma vez que tende a territorializar o feminino. Além desta primeira identidade, e lembrando com alguma ironia o poema "Se me quiseres Conhecer", de Noémia de Sousa; a poeta assume a sua africanidade: "dizes que me querias sentir africana/ dizes e pensas que não o sou,/ só porque não uso capulana,/ porque não falo changana,/ porque não uso missiri nem missangas,/ deixa-me rir...". Quer este poema desenhar um percurso identitário de abertura às diferenças de género, de raça, de língua e de cultura, num continente e num país, que se caracteriza também pela coexistência harmónica de tal múltipla diversidade: "pelo sangue que me corre nas veias,/ negro, árabe, indiano,/essa mistura exótica, que me faz filha de um continente em tantos/ onde todos se misturam,/ e que me trazem esta profundidade,/ mais forte que a indumentária, ou a fala,/e sabes porquê?/ porque visto, falo, respiro, sinto e cheiro a África,/ afinal o que é que tu saberás? O que é que tu sabes?? (IP, p.15).

Interrogativa, reticente, dialogal, esta voz percorre os poemas como o sangue nas veias de um corpo amoroso, palavras que são o próprio sujeito em aeto de constituição e de revelação: "As palavras que te dou/ são o que sou,/ são o que sinto,/ e como me sinto,/essas são as minhas palavras EU" (IP, p.29).

No Colo da Lua, terceiro livro de poemas de Sónia Sultuane, testemunha uma plenitude de alguns dos atalhos percorridos na aetividade artística, simultaneamente espiritualizada por uma introspecção dos sentidos e dos sentimentos. Há nestes poemas a procura de harmonia de um corpo que quase voa, na sua aspiração ao sonho e à verdade, à pureza das sensações, à celebração do desejo. O poema que dá título ao livro, "No colo da Lua", diz-nos da apetência amorosa, de expansão e abertura do sujeito ao mundo, ao universo inteiro, da vontade da poeta falar às estrelas, se aninhar no colo da lua, o mágico planeta da noite que a enfeitiça, e que transfigura o sonho em realidade: 
"Quero olhar o céu/ e contemplar a sua sombra dançando/ na cadência do meu coração,/ mergulhar no seu infinito,/ no reflexo do azul esverdeado profundo,/sentir o cheiro do mundo percorrer-me as entranhas,/ falar às estrelas prateadas,/ sentar-me no colo da lua amando a imensidão do universo,/ saboreando cachos de uvas pretas adocicadas,/ para poder entregar-me a todos os sabores exóticos,/cantando e suspirando pela vida" (CL, p.11).

A experiência sensorial torna-se quase um aeto de levitação graciosa em torno das coisas, corpo alado, cujas asas ou pétalas acariciam o que tocam, e no que é tocado se sentem acariciadas. O corpo vive dessa dualidade de ser por um lado, quase imaterial, é dança, música, sopro, flor, pétala, esvoaçante, como se pode ler em vários poemas, como por exemplo, "Noiva": "Danço nas sombras do luar prateado,/ visto-me de sari vermelho bordado com missangas douradas/trazidas de Bombaim/nas árvores imaginárias de vida/ penduro os meus cabelos que esvoaçam na brisa/ trançados com folha de laranjeira e jasmim (...)"(CL, p.12).

O movimento aéreo de leveza retoma Sonhos, o primeiro livro, e leiam-se os poemas "Se Soubesse Voar", "Gaivota" ou "Liberdade", como experiências desta volição volátil, que se combina com outro elemento, o aquático, ritualizado em purificação e embelezamento, como se expressa em "Pétalas": "Banhei o meu corpo com pétalas de rosas vermelhas,/ o cheiro exótico do deserto e o óleo da sedução,/entrei na tenda do desejo/ cheirando a rosas e a incenso da imaginação,/entreguei-me, no meu leito coberta de sedas,/ tão leves como a ilusão (...)" (CL, p.37). Repare-se como os diferentes sentimentos, sejam de desejo, separação ou tristeza, ilusão ou encantamento, são ductilizados e irmanados em subtil e cuidadosa evocação, com imagens harmónicas e sensualizadas.

Associados na descrição, são referidos vários elementos delicados do oriente, que percorrem os poemas de Sónia Sultuane, como os tecidos, os ornamentos, as essências e perfumes, as evocações florais: "No lago das orquídeas deitadas/ banhei-me à conversa com as flores de lótus/ baixinho, diziam-me que os cisnes/dormiam embalados com a música das folhas / trazidas pela corrente do sul,/ pediram- que me banhasse tranquila/ pois a brisa do sol,/ embebedava-as com o meu perfume/a noz-moscada e flor-de-lis/ pediram que entrelaçasse-me as águas cristalinas/para que o meu cheiro não assustasse/ nas margens do lago as borboletas que nasciam" (CL, p.9). 
Ao mesmo tempo, o corpo, entrançado na sua matéria, comunga da suculência dos frutos e do inebriamento olfaetivo dos odores de diversos aromas. Em apetecidos poemas como "Essa Boca Linda", "Noites de Prazer" ou "Manjares Exóticos", se expressa a frutificação do desejo, lembrando o par inicial que, no paraíso, provou o fruto proibido e experimentou a tentação do amor: "Saboreias no meu corpo o gosto do amor,/ nos meus mamilos dou-te o gosto do morango carnudo,/no meu ventre o gosto de abacaxi (...)"(CL, p.5).

Há uma celebração assumida do prazer e do desejo físico, da comunhão dos corpos, que a escrita feminina de Sónia Sultuane assume, voluptuosamente. Inebriado, em "Noites de Prazer", o sujeito poético confessional, escreve que não se arrepende de ter transformado um sentimento como o amor na grandeza do seu ser: "não me arrependo (....) De não ter seguido e queimado as etapas da vida,/mas de ter vivido a vida conforme as etapas/ e o fogo do meu coração, (...). De não ter sucumbindo à vontade carnal,/mas ter amado com a alquimia dos sentidos,/ de não ter deixado o meu coração/ser uma armadilha,/mas ser a presa dos meus sentimentos (...)"(CL, p.4).

Mas, envolvidos nesta linguagem de tules e sedas esvoaçantes, outros temas perpassam na poesia de Sónia Sultuane: a maternidade, a infância, a igualdade das mulheres, a espiritualidade. Temas ritmados ao som de pautas de música, da valsa ao jazz, com os movimentos sentimentalmente sofisticados do tango: "danço o tango dos sentimentos", diz-nos a poeta; ou em combinatória irizada de escritas, como num lento jogo de sombras enluarado, regista-se ainda uma sonâmbula evocação de quem nasceu poeta, e se embriaga de poesia e de "poetas invisíveis e imaginários" (CL, p.2).

"Essa Boca linda, suculenta e carnuda, "esse manjar de néctares" vem enriquecer, pela enunciação de Sónia Sultuane, a poesia moçambicana de uma emoção de sincero fingimento e de voluptosa feminilidade.

\section{Ser de escrita, deambulação e música na poesia de Chagas Levene}

Tatuagens de Estrelas, de Chagas Levene, é um livro em que o sujeito deambula observando paisagens interiores e exteriores, reflectindo, perplexo, pelo estado das coisas na sua terra: fome, desemprego, prostituição, corrupção, violência, droga. 
Mas a dicção do sujeito é calma, fragmentário o comentário, por vezes quase como que uma anotação de diário. O curioso título "Nos bolsos levo só poemas", além da sua carga metapoética, poema por dinheiro, poesia por bens materiais, a indicação do hábito da anotação breve e importante, que o bolso guarda.

Entre o som das teclas da escrita e dos tiros a homologia torna-se abrupta e trágica: "Neste mundo em que as metralhadoras/ batem mais rápido seus textos/ do que uma máquina de escrever/ nos bolsos levo só poemas / para reacender as estrelas de madrugada" (TE, p.10). Outros poemas como "Bum Bum Bum cada mina mata um/ Lá na terra da mamã tem um campo com minas/ quem pisou morreuuuu (...) (TE, p.66), ou "Ra Tá Tá AKM mata Pá", introduzem-nos num universo, em que a violência das armas e da morte é absurdamente normalizada no quotidiano, como um jogo infantil, ou ao ritmo da canção. "Querem que eu dance a canção martelada de uma arma?/ querem que eu troque a discoteca por um gatilho?//Os pássaros voam festejam a vida/ na outra esquina está uma arma a gritar/ / Hoje não ficarei na cidade/ vou correr pelos campos / para soltar pássaros engaiolados" (TE, p.74).

A violência deste "locus horrendus" é assim tentadamente substituída pela procura de um "locus amoenus", no campo, nos jardins, junto aos rios, onde o sujeito se desencanta na procura do amor. Confessionalmente reflecte sobre ele em "O Amor é um Rio", "A ver as Nuvens", "Canção de Embalar na Estação Seca", "A Lua a servir-me de Travesseiro", "Beijos teus só os tive imaginados", "Tatuar teu corpo de estrelas", entre vários outros, num misto de ironia e desentendimento, recorrendo a uma escrita entrecortada de uma intelectualizada emoção, quase à maneira melancólica e desprendida de Ricardo Reis. "É preciso amar nem que não haja estrelas// Vamos entrelaçar nossas mãos/correr até ao ancoradouro do rio/ lá as árvores são grandes/ belas para nos fazerem sombra/ vamos lá sentar-nos para ver os barcos/a rasgarem o rio mais que incêndio em capim seco/ / Teu sorriso ampara como muralha a uma cidade / / Nossas mãos uma na outra abrem-me o mundo (...) chovem estrelas dos teus olhos/ cubro-me com esse manto/ e de noite deitome com a lua/ a servir-me de travesseiro" (TE, p.20).

Ao mesmo tempo há na emoção de Levene uma pureza, quase inocente e credível, na beleza do sonho, que as imagens das estrelas convocam, entremeadamente, em muitos poemas. As estrelas povoam a poesia do autor, 
enquanto brilho redentor, e quase impossível, da noite estrelada em brilho enlouquecido da tela de Van Gogh, que serve de capa ao livro. Perguntamonos, é necessário o brilho na madrugada, porque ela escureceu?

O poeta olha o mundo como no poema "Passarela", observando: "quando a lua minguada se excita cinzenta/ vem uma rameira criança arranca um cravo/ coloca por baixo do seu grande decote em u/ nisso a lua ilumina-a mostrando seus lábios...” (TE, p.12). Muitos textos evocam o tema da prostituição, relembrando a poesia de Craveirinha, como por exemplo em "Vários Braços tem o Poema": "Veste-te como puderes Zézinha/ retoca-te antes maquilha-te a rua quer-te invulgar/ desculpa os versos do tempo que se foram (...) teu corpo despido/ um poema antigo (...) (TE, p.27). Congeminando preferir "ser poema a poeta", a "querer viver com palavras"; diz-nos: "Meu Deus o que é a poesia?// Sinto-me deprimido e com a gaveta a abarrotar de papéis/ tenho uma alma de papel e tinta vinda dos livros que li/ dos livros também tenho a forma do meu corpo/ uma forma de papel" (TE, p.14).

Pessoano, impessoal, máscara e idealização de ser, o poeta, que usou a heteronímia, em publicações anteriores em revistas, é um ser de escrita por excelência. A singularíssima enunciação de Chagas Levene retoma também um intertexto, que oscila entre os ritmos populares urbanos e musicais de Gabriel o Pensador, por exemplo, o hip hop, sungura, e a incorporação da herança literária de Fernando Pessoa, Armando Artur, Eduardo White.

O poema de abertura "Mtsitso" incorpora formal e tematicamente o poema "Quero ser tambor" e "Karingana wa Karingana" de José Craveirinha e introduz um subliminar intertexto craveirínhico, que perpassa, como linha condutora, por muitos dos seus poemas deste primeiro e também do segundo livro: "Mãe/ esta noite está a erguer-se com estrelas/ muito mais do que aquelas das estórias/ à volta da fogueira// São mais que cem/ são mais que mil/ são incontáveis/são infindáveis// Mãe/ eu quero uma mbila de papelão/ se não puder ter uma verdadeira/ para tocá-la/ e subir através dos seus sons/ até às estrelas" (TE,p.9).

Em Porto de Luz̧es, a segunda colectânea do autor, os brilhos entrelaçamse, num jogo pictural e imagético, com a água, provocando tensão e também harmonia. A escrita é uma "Dança num deserto", entre viagem, voo e luz, navio, estrela e infinitude, sabendo o poeta que a liberdade se conjuga dramaticamente: "Uma vida trágica/ mas cheia de magia e borboletas". 
Chagas Levene, por entre uma dicção confessional e perplexa, revela a consciência da herança literária recebida, em fogo de escrita - a recepção do facho a que Noémia de Sousa aludia no seu poema sobre Rui de Noronha - agora, na sua poesia ancorada, porto de luzes, que teima em fazer luzescrever, embora com desencanto, essa voz colectiva, nacional, de esperança. Os sentidos do livro retomam alguma utopia ascensional, com metáforas delicadas como nuvens, estrelas, papagaios de papel. A borboleta hieroglífica, em seus trajectos, uma mensagem histórica e literária, a perdida "morada azul das canções": "Sou tudo o que antes de mim outros foram/ por isso dei-te as borboletas roubadas de colecções raras/ para que compreendas a dor de um ser que já não voa// Antes de mim outros transformaram o silêncio em palavras/e deram-me a morada azul das canções".

A escrita do poeta torna-se assim, além de lugar de memória e de interrogação, de desejo e de sonho, espaço de reencontro do sujeito com a sua arte poética, espécie de "Pirotecnia", em que a estrela reverbera, tatuada em papel, e em que a representação do fogo herdado, refeito em escrita, teima oximoricamente em animar o cosmos da subjectividade do sujeito: "A minha tristeza é a felicidade/ com que construo a pirotecnia dos meus poemas".

A poesia será para Levene uma forma-abrigo - porto de luzes - criada para compensar a desadequação entre o ser e o mundo: "Em meus bolsos existem castelos escandalosos de estrelas!/ Meus olhos há muito que ardem em pântanos,/ como as estrelas em meus poemas./ Agora eu brilho brilho brilho/ como se fosse uma invenção minha”. A fractura existente entre o sujeito e a realidade social leva o poeta a usar a palavra para criar um mundo alternativo, fazer-se matéria e cosmos verbal: "Em meus olhos ainda arde a esperança/ De pegar-te pela cintura como a um poema pela manhã".

\section{Viagem, memória e loucura na poesia de Celso Manguana}

O livro de Celso Manguana Pátria que me Pariu provoca no leitor um singular espanto em ler, de forma simples, escandida em verso breve, uma certeira crítica social, visível logo a partir do trocadilho que o título propõe, representativa de uma geração desencantada com as mudanças do projecto político do país. 
Este conjunto de poemas está organizado em duas partes complementares, mas diversas. A primeira organiza-se com um conjunto de poemas, que poderíamos apelidar de epigramáticos, em que a temática é convertida em palavras-chave, nelas condensada por uma técnica de repetições. Os poemas articulam sintacticamente proposições simples e directas, que actuam com o desdobramento paralelístico de uma só figura rítmica, e realizam o máximo de intensidade de significação num mínimo de espaço de verso.

Diria Zenão que a brevidade é um estilo que contém o necessário para manifestar a realidade, adequado para carecterizar o discurso de Celso Manguana. Termos como rigor, despojamento, concisão, substantividade, arquitectura e mesmo geometria servem esta poesia epigramática, que tem o valor da frase inscrita na lápide, recolhendo a moralidade da lucidez crítica antiépica e anti-heróica. Mas, simultaneamente a uma certa enxutez da asserção, confere-lhe o poeta um ritmo refrânico e cantante pelo uso da rima externa e interna: "Pátria/ quero só uma/ o lugar de/ morte/A nenhuma/ cidadania/ pertenço/ conheço/ três/ lugares/ de exílio/ O amor/A memória/A loucura/ Memória/ percorrida/ loucura/ visitada/ e quantos/ amores// Vou/ para norte/ sempre/ para morte/Caminho/ sozinho/ não/ despeço/ peço/ lume/ Charro/ aceso/ prossigo/ para/ norte/ obviamente/ para/ morte/ (minha pátria)" (PQMP, p.2).

Ao fazermos uma identificação das palavras-chaves-temas mais significativas do livro, encontramos no primeiro poema o "programa" que orienta esta escrita: pátria, morte e três lugares substantivos de exílio (amor, memória, loucura).

É nesta travessia ou itinerário poético que Celso Manguana começa por intertextualizar o cancioneiro épico da literatura de combate, revertendo a significação utópica em distopia - "Vou/ para norte/sempre/para morte... charro/ aceso/ prossigo/ para/ norte/ obviamente/ para/ morte (minha pátria)". Invertendo a direcção, de sul para norte, o poema de Celso, talvez por razões objectivas (lembrando a necessidade de revitalizar o norte do país) inflecte um deslocamento e direcciona, no sentido contrário, do centro para a periferia, o percurso de um dos emblemas da poesia revolucionária, que saudava a conquista a partir do movimento norte-sul.

Leia-se, por exemplo, Eu o Povo de Mutimati Barnabé João, nomeadamente o poema "Para Sul" ("Na noite em que passámos o rio Rovuma/ Apontei para Sul com o nariz, com o coração, com os pés...”). Ao colectivo da viagem 
de conquista do país, sucede agora a individualidade de um percurso pessoal, em demanda dos lugares de "exílio", de fuga e de achamento de si.

Mas Pátria que me Pariu é também o título de um texto de Gabriel o Pensador sobre a sua terra, o Brasil, recuperado intertextualmente pelo poeta moçambicano. A duplicidade de leitura, cancioneiro épico e texto música, permite ajustar a componente popular da poesia de combate com o ritmo rap.

A pátria "Sonâmbula" (e veja-se a referência implícita ao romance Terra Sonâmbula), poema dedicado aos pais, refere a amarga evidência da fome: "acorda/ com/ fome// Custa amar/ uma bandeira/ assim// Tem/ o/ amargo/ gosto/ do asilo// Almoço/ de pão/ com badjias/ sabe bem/ todos/ os dias?" (PQMP, p.5). Repare-se na ironia da interrogação retórica, que revitaliza a interrogativa crítica do verso craveirínhico, e que surge em vários outros poemas, como por exemplo no poema à memória de Samora Machel e de Carlos Cardoso: "Quanto custa/ quanto custa mesmo/ amar a liberdade? ..Que dizer/ da vida/ quando/ Mesmas/ armas/ libertam/e/ também/ matam?" (PQMP, p.8)

A demanda da pátria, do sonho, da paz sem armas, da ausência de violência, não se confronta coma realização destes ensejos: "Mas sonhamos/ talvez/ sonhamos// Só a meia-haste// meninos/ regressamos/ a/ Nachingweya/ não/ temos armas// Procuramos a Pátria.” (PQMP, p.8).

Falamos de um itinerário poético, programaticamente caracterizado pela demanda de um mundo substantivo, socialmente amoroso, que faz do poema dedicado à memória de Siba-Siba Macuácua, a confissão do crédito de um amor maior, embora cepticamente desacreditado: "Esta coisa/ de deixar/ que o amor/ a bandeira/ de Junho/ seja o/ amor/ primeiro// E como cega/ todo o amor/ sincero!"'.O poeta regressando ao tema, diz mais adiante, em outro poema: “Onde o amor/ florescer/ a pátria pode/ nascer...” (PQMP, p.11).

O ritmo escandido dos poemas, palavra a palavra, na sua simplicidade solene, de efeméride aos mortos, epigramática e refrânica, evoca ainda Zaida Lchongo, e a implicação festiva e social das letras e dos ritmos das canções da artista.

A serialização dos poemas de Celso Manguana, realiza-se pela insistência temática e formal, e o gume da crítica social não se deixa amortecer pela nostalgia, embora o reduto do sonho, os lugares de exílio, entre os quais a infância, criem fortes imagens oníricas: "A infância/ minha outra/ Pátria// Às vezes/ quero/ lá voltar// com sal/ amadurecer as mangas(...)Talvez seja 
só/ para ver/ o papagaio/ da minha/ meninice/ a voar/ no mar/ no tempo/ e pousar/ no futuro" (PQMP, p.6). São visíveis as referências aos poemas knopflianos de Mangas verdes com sal nesta evocação da infância, gostosamente assumidos numa herança de escrita.

Técnica de repetições, andamento anafórico e paralelístico, reiteração topológica de palavras iguais ou parónimas, repetição de tipo aliterativo, ou em eco, a poesia de Celso Manguana testemunha um certo humor, extraído de uma ágil manipulação de sintagmas directamente extraídos do falar coloquial, assim como afirma que a quase nudez vocabular, longe de ser um pejorativo estético, pode constituir-se num legítimo princípio de estilo, que tem o pudor das exterioridades gritantes e leva ao despojamento.

"Sobre amor/escrevo noutros/ versos" diz o poeta. E a segunda parte do livro cumpre esta afirmação. O ritmo muda, e os textos em prosa poética, mais longos e extensivos, preparam-se para um tom assumidamente lírico e confessional: "Vem de dentro este frio. Do lado esquerdo lado do peito. Como se aplaca este frio que vem do coração?” (PQMP, p.23).

$\mathrm{O}$ encadeamento de motivos, o envolvimento do eu lírico e do eu participante, da vivência amorosa e da convivência política, opera-se não por um pacto exterior, mas por dentro, na textura da linguagem, o que lhe confere uma singular eficácia. Assim, a espera do amor, a esperança, o desespero, a diarística amorosa do sujeito emocionado, cruza-se em imagens da fragilidade do mundo social/individual, em simbiose de forte comoção (déficit económico e amoroso): "Esperar. E esperar. Do chapa-100. Há Chapa-100 que nos leva para o amor?" (PQMP, p.28).

\section{Referência Bibliográfica}

LEVENE, Chagas. Tatuagens de Estrelas. Maputo: Ndgira, 2007.

LEVENE, Chagas. Porto das Luzes. Maputo: Ndgira, 2010.

MANGUANA, Celso. Pátria que me Pariu. Maputo: Fundac, 2008.

SECCO, Carmen Lúcia Tindó, A Magia das Letras Africanas. Rio de Janeiro: Quartet

Editora\&Comunicação Ltda, 2008.

SULTUANE, Sónia. Sonhos. Maputo: Ndgira ,2001

SULTUANE, Sónia. Imaginar o Poetizado. Maputo: Ndgira,2006.

SULTUANE, Sónia. No Colo da Lua. Maputo: Ndgira,2009. 